\title{
Modeling continuous cultures of microalgae colimited by nitrogen and phosphorus
}

\author{
Gaël Bougaran ${ }^{\mathrm{a},{ }^{*}}$, Olivier Bernard ${ }^{\mathrm{b}}$ and Antoine Sciandra ${ }^{\mathrm{c}, \mathrm{d}}$
}

\author{
${ }^{a}$ PBA-IFREMER, rue de l'lle d'Yeu, BP 21105, 44311 Nantes cedex 03, France \\ ${ }^{b}$ COMORE-INRIA, BP93, 06902 Sophia-Antipolis Cedex, France \\ c Université Pierre et Marie Curie, Université Paris 06, Unité Mixte de Recherche 7093, Laboratoire \\ d'Océanographie de Villefranche, Villefranche-sur-Mer, France \\ ${ }^{d}$ Centre National de la Recherche Scientifique, Unité Mixte de Recherche 7093, Laboratoire d'Océanographie de \\ Villefranche, Villefranche-sur-Mer, France
}

\author{
*: Corresponding author: G. Bougaran, Tel.: +33 024037 41; fax: +33 02403740 73, email address : \\ gael.bougaran@ifremer.fr
}

\begin{abstract}
:
It is well documented that the combination of low nitrogen and phosphorus resources can lead to situations where colimitation of phytoplankton growth arises, yet the underlying mechanisms are not fully understood. Here, we propose a Droop-based model built on the idea that colimitation by nitrogen and phosphorus arises from the uptake of nitrogen. Indeed, since N-porters are active systems, they require energy that could be related to the phosphorus status of the cell. Therefore, we assumed that $\mathrm{N}$ uptake is enhanced by the $\mathrm{P}$ quota. Our model also accounts for the biological observations that uptake of a nutrient can be down-regulated by its own internal quota, and succeeds in describing the strong contrast for the non-limiting quotas under $\mathrm{N}$-limited and P-limited conditions that was observed on continuous cultures with Selenastrum minutum and with Isochrysis affinis galbana. Our analysis suggests that, regarding the colimitation concept, $\mathrm{N}$ and $\mathrm{P}$ would be better considered as biochemically dependent rather than biochemically independent nutrients.
\end{abstract}

Keywords: Colimitation; Phytoplankton; Mathematical model; Quota 


\section{Introduction}

Nitrogen and phosphorus are major nutrients that are likely to limit growth of phytoplankton in the natural environment (Bergstrom et al., 2008; Davey et al. 2008, Persic et al. 2009). Situations of colimitation where both $\mathrm{N}$ and $\mathrm{P}$ resources are simultaneously low enough to limit growth have also been reported (Suttle and Harrison, 1988; Elser et al. 1990, Maberly et al., 2002, Ren et al. 2009; Zohary et al. 2005). These two nutrients play a major role in the cell metabolism as they are part of many biochemical processes. Cell nitrogen is mainly used to build proteins, amino acids and nucleic acids while phosphorus is mostly a constituent of nucleic acids and phospholipids (Geider and LaRoche, 2002). From a functional point of view and according to the terminology of Klausmeier et al. (2004a), the assembly machinery is rich in nitrogen and phosphorus, while the acquisition machinery (pigments and porters) is poor in phosphorus but rich in nitrogen. Although nitrogen and phosphorus are important constituents of the biomass, smaller pools of phosphorus in ATP and NADP also play a major role in the energetic processes.

Since the 70s, several studies have focused on how interactions between nutrients could affect the growth of phytoplankton. Two major models were tested to describe multi-nutrient limitation. The multiplicative model assumes that all nutrients for which the corresponding cell quota is not full contribute to growth limitation. This approach assumes that several nutrients can control growth simultaneously. In cases where several nutrient-quotas are suboptimal the multiplicative model can produce very depressed growth predictions. On the other hand, the threshold model (also called the minimum law) states that growth is always controlled by a single nutrient whose quota is the lowest relative to the actual needs of the cell (i.e. the lowest quota relative to the subsistence quota). This model therefore excludes nutrient colimitation for growth. Droop (1973, 1974), who worked on the interaction between vitamin $B_{12}$ and phosphorus on Monochrysis lutheri, first demonstrated that growth rate was limited 
by the most limiting nutrient. Rhee (1978) achieved the same conclusion on Scenedesmus sp. with nitrogen and phosphorus. Terry (1980), Elrifi and Turpin (1985) and Leonardos and Geider (2005) also argued in favor of modeling growth rate based on the minimum law.

On the other hand, N-P colimitation has frequently been invoked in the natural environment where it was demonstrated that $\mathrm{N}$ and $\mathrm{P}$ had to be available together in order to promote growth of the phytoplankton community (Maberly et al., 2002, Seppala et al. 1999 , Zohary et al., 2005). Some laboratory experiments on monospecific cultures also gave evidence of more complex N-P interactions. For example, Davies and Sleep (1989) demonstrated that carbon fixation of $\mathrm{N}$ and $\mathrm{P}$ starved Skeletonema costatum could be significantly stimulated only when both $\mathrm{NO}_{3}^{-}$and $\mathrm{PO}_{4}^{3-}$ were added simultaneously, but was repressed when only $\mathrm{NO}_{3}^{-}$was added. Terry (1980) suggested that, while the minimum law prevailed for most N:P ratios, a synergetic effect on Pavlova lutheri could occur between the two nutrients in a narrow range of $\mathrm{N}: \mathrm{P}$ ratio. Because no clear biochemical process of interaction could be identified between nitrogen and phosphorus metabolism, these two nutrients were previously classified as biochemically independent nutrients (Arrigo, 2005, Saito et al., 2008). Recently, however, Agren (2004) hypothesized that the P-content of ribosomes could perform the main link between $\mathrm{N}$-assimilation and $\mathrm{P}$ quota. Under this hypothesis, Pahlow and Oschlies (2009) proposed a modeling approach of N-P colimitation where they categorized $\mathrm{N}$ and $\mathrm{P}$ as biochemically dependent, but the mechanisms leading to a physiological state where both nitrogen and phosphorus interfere for growth were not fully elucidated.

Here we propose a Droop-based model based on the idea that colimitation between nitrogen and phosphorus could arise from the uptake of nutrients rather than from the strict growth function. This model is an extension of the model studied by Klausmeier et al. (2004b). The proposed model resulted from a recursive reverse engineering approach, where a mathematical analysis guided 
the choice of model structure so that the model finally satisfies some qualitative properties. However, for sake of clarity, only the final version of the model is presented and justified, and we demonstrate that its mathematical behavior structurally (i.e. independently of the choice of parameter values) matches the data trend. The mathematical developments that guided the modifications of the Droop model in order to end up with a colimitation model that presents an asymmetric response between N-limited and P-limited culture are therefore not detailed, and we refer the reader to Bernard et al. (2008) for an illustration of this approach.

We demonstrate the ability of our model, which is an extension of Bougaran et al. (2009), to produce a correct quantitative and qualitative representation of the experimental data obtained on Selenastrum minutum by Elrifi and Turpin (1985) and our own data on Isochrysis affinis galbana. We further compare the model output to the original model of Klausmeier et al. (2004b). Finally, we discuss the different modeling approaches for N-P colimitation and the biological basis for our model.

\section{Material and methods}

\subsection{Isochrysis affinis galbana}

Isochrysis affinis galbana CCAP 927/14 was grown in $2-L$ photobioreactor chemostats (Bougaran et al. 2003) at dilution rate ranging from 0.1 to $1.1 d^{-1}$ under different $N: P$ ratios. Cultures were illuminated with continuous light $\left(130 \mu \mathrm{mol} . \mathrm{m}^{-2} . \mathrm{s}^{-1}\right)$, temperature was maintained at $27^{\circ} \mathrm{C}$ and $\mathrm{pH}$ at 7.2 . The Walne medium was modified so as to obtain $\mathrm{N}$ - or P-limited medium: for the N-limited medium, $\mathrm{NaNO}_{3}$ was decreased from $1120 \mu M$ to $115 \mu M(N: P$ $=0.7)$; for the P-limited medium, $\mathrm{NaH}_{2} \mathrm{PO}_{4}$ was decreased from $159 \mu \mathrm{M}$ to 8 $\mu M(N: P=137)$. Six cultures were grown under $\mathrm{N}$ limitation and 4 under $\mathrm{P}$ limitation.

All measurements were made on culture samples at steady-state. Chemical analysis of residual $\mathrm{N}$ and $\mathrm{P}$ concentrations were carried out on a DIONEX ion-chromatography (AS9-HC column). $\mathrm{C}$ and $\mathrm{N}$ quotas were measured on a 
CHN-elemental analyzer. $\mathrm{P}$ quota $\left(\right.$ denoted $\left.q_{P}\right)$ was estimated at steady-state from residual phosphate concentration (1):

$$
q_{P}=\frac{p_{\text {in }}-p}{x}
$$

where $p_{i n}$ is the phosphate concentration in the renewal medium, $p$ is the residual concentration of phosphate in the culture medium and $x$ the carbonbiomass at steady-state.

\subsection{Selenastrum minutum}

Elrifi and Turpin (1985) grew Selenastrum minutum under phosphate or nitrate limitation in axenic chemostats, with dilution rate ranging from 0.1 to $1.7 d^{-1}$. A constant photon flux density of $100 \mu \mathrm{mol} . \mathrm{m}^{-2} \cdot \mathrm{s}^{-1}$ was provided at the surface of the culture. Nitrate-limited medium was supplied with $100 \mu M$ $K_{N O}$ and $100 \mu M N_{2} \mathrm{HPO}_{4}(N: P=1)$, whereas phosphorus limited medium was enriched with $2000 \mu M K O_{3}$ and $10 \mu M N a_{2} H_{P O}(N: P=200)$. Particulate carbon and nitrogen were measured on an elemental analyzer, whereas particulate phosphorus was analyzed following Afghan (1982). The data of Elrifi and Turpin (1985) were digitalized (using Epson 1640 SU scanner) and the C-based quotas were computed.

\section{Model development}

\subsection{Presentation of the Droop model}

The most widespread model to reproduce growth of microalgae under substrate limitation is the Droop model (Burmaster, 1979, Droop, 1968b, 1983). It is widely used since it reproduces the ability of microalgae to uncouple substrate absorption and growth. Its simple structure made it possible to study and mathematically characterize its behavior (Bernard and Gouzé, 1995; Lange and Oyarzun, 1992, Vatcheva et al., 2006). However, when both nitrogen and phosphorus are at suboptimal growth level at the same time, a new model must be designed.

In contrast to the Monod model, the Droop model (Droop, 1968b, 1983) states 
Table 1: Parameters used for model of N-P colimitation.

\begin{tabular}{|c|c|}
\hline Parameter & Meaning (units) \\
\hline$x$ & carbon-biomass $\left(\right.$ mol.L $\left.^{-1}\right)$ \\
\hline$\mu_{\max }$ & maximum growth rate $\left(\right.$ day $\left.^{-1}\right)$ \\
\hline $\bar{\mu}$ & hypothetical growth rate when quota is infinite $\left(\right.$ day $\left.^{-1}\right)$ \\
\hline$D$ & dilution rate $\left(\right.$ day $\left.^{-1}\right)$ \\
\hline$n_{\text {in }}$ & nitrate concentration in the renewal medium $\left(\right.$ molN.L $\left.{ }^{-1}\right)$ \\
\hline$p_{\text {in }}$ & phosphate concentration in the renewal medium $\left(\mathrm{molP} . \mathrm{L}^{-1}\right)$ \\
\hline$n$ & ambient nitrate concentration (molN.L $\left.{ }^{-1}\right)$ \\
\hline$p$ & ambient phosphate concentration (molP.L ${ }^{-1}$ ) \\
\hline$q_{N}$ & nitrogen quota (molN.molC $\left.{ }^{-1}\right)$ \\
\hline$q_{P}$ & phosphorus quota (molP.molC ${ }^{-1}$ ) \\
\hline$q_{N e x p}$ & nitrogen quota at $\mu_{\max }\left(\operatorname{molN} . m o l C^{-1}\right)$ \\
\hline$q_{P \exp }$ & phosphorus quota at $\mu_{\max }$ (molP.molC ${ }^{-1}$ ) \\
\hline$q_{N 0}$ & nitrogen subsistence quota (molN.molC ${ }^{-1}$ ) \\
\hline$q_{P 0}$ & phosphorus subsistence quota (molP.molC ${ }^{-1}$ ) \\
\hline$q_{N L}$ & hypothetical maximum nitrogen quota (molN.molC ${ }^{-1}$ ) \\
\hline$q_{P L}$ & hypothetical maximum phosphorus quota (molP.molC ${ }^{-1}$ ) \\
\hline$\rho_{N}$ & nitrate uptake rate $\left(\right.$ molN.molC ${ }^{-1} \cdot$ day $\left.^{-1}\right)$ \\
\hline$\rho_{P}$ & phosphate uptake rate (molP.molC ${ }^{-1}$. day $^{-1}$ ) \\
\hline $\bar{\rho}_{N \max }$ & nitrate maximum uptake rate (molN.molC ${ }^{-1}$. day $\left.^{-1}\right)$ \\
\hline $\bar{\rho}_{P \max }$ & phosphate maximum uptake rate (molP.molC ${ }^{-1} \cdot$ day $^{-1}$ ) \\
\hline$K_{s N}$ & half saturation constant for nitrate uptake $\left(\right.$ molN.L $\left.^{-1}\right)$ \\
\hline$K_{s P}$ & half saturation constant for phosphate uptake (molP.L $\left.{ }^{-1}\right)$ \\
\hline
\end{tabular}

that growth of a phytoplanktonic population characterized by its carbon biomass $(x)$ is related to the cell quota $(q)$ of the limiting nutrient rather than to ambient extracellular concentration. When considering nitrogen in a chemostat the Droop model can be written as follows:

$$
\left\{\begin{array}{l}
\dot{n}=D n_{i n}-\rho_{N}(n) x-D n \\
\dot{q_{N}}=\rho_{N}(n)-\mu\left(q_{N}\right) q_{N} \\
\dot{x}=\mu\left(q_{N}\right) x-D x
\end{array}\right.
$$

where $q_{N}$ is the internal carbon-based quota of nitrogen, $D$ is the dilution rate of the chemostat, and $n$ and $n_{i n}$ are the concentrations of inorganic nitrogen in the culture medium and in the renewal medium, respectively. The functions $\rho_{N}$ and $\mu$ represent inorganic nitrogen uptake and growth rate, respectively.

With a phosphorus limitation, the model is written: 


$$
\left\{\begin{array}{l}
\dot{p}=D p_{i n}-\rho_{P}(p) x-D p \\
\dot{q_{P}}=\rho_{P}(p)-\mu\left(q_{P}\right) q_{P} \\
\dot{x}=\mu\left(q_{P}\right) x-D x
\end{array}\right.
$$

In this model the specific uptake rate $\rho$ and growth rate $\mu$ are MichaelisMenten and Droop functions, respectively:

$$
\begin{aligned}
\rho(s) & =\rho_{m} \frac{s}{s+K_{s}} \\
\mu(q) & =\bar{\mu}\left(1-\frac{q_{0}}{q}\right)
\end{aligned}
$$

Where $K_{s}$ is the half saturation constant for uptake, $\rho_{m}$ is the maximum uptake rate, $q_{0}$ the minimal subsistence quota of starved cells for the limiting nutrient and $\bar{\mu}$ the hypothetical maximum growth rate obtained for an infinite value of the quota for the limiting nutrient.

It can be proved (Bernard and Gouzé, 1995) that the internal quota for a limiting nutrient stays between two bounds

$$
q_{0} \leq q \leq q_{\exp }
$$

Then, $q_{\exp }$, the maximum quota obtained at maximum growth rate $\left(\mu_{\max }\right)$ (Bernard and Gouzé, 1995) can be computed:

$$
q_{\exp }=q_{0}+\frac{\rho_{m}}{\bar{\mu}}
$$

and finally the maximum growth rate is $\mu_{\max }=\mu\left(q_{\exp }\right)$.

Remark 1: in the following, we will write :

$$
\mu_{\max }=\bar{\mu}\left(1-\frac{q_{0}}{q_{e x p}}\right)
$$

At steady-state, the internal quota is an increasing function of the dilution rate:

$$
q^{\star}=q_{0} \frac{\bar{\mu}}{\bar{\mu}-D}
$$

where the ${ }^{\star}$ denotes the value at steady state.

This model has been validated in depth and has been proved to be relevant (Droop, 1983 Sciandra and Ramani, 1994) to represent conditions of nitrogen 
or phosphorus limitations even in dynamic influent conditions (Bernard et al. 1998, Bernard and Gouzé, 1999).

\subsection{Extension of Droop's model to handle colimitation}

As in Klausmeier et al. (2004a), we propose to modify the Droop model in order to handle colimitation by nitrogen and phosphorus. Klausmeier et al. (2004a) categorized the various growth processes into the acquisition and assembly machineries. The acquisition machinery that combines pigments and membrane porters is N-rich but P-poor; we will however consider that phosphorus may play a major role at the acquisition level since it is involved in the active uptake of both nitrogen $\left(\mathrm{NO}_{3}^{-}\right)$and inorganic phosphorus. Conversely, the assembly machinery corresponds to ribosomes and is N and P-rich. Consequently, we now state the general assumptions that uptake of a given nutrient is function of both its external concentration and the internal quota of both nutrients. We also assume that growth rate can be driven by either the nitrogen or the phosphorus quota. The resulting generic model is as follows:

$$
\left\{\begin{array}{l}
\dot{n}=D n_{i n}-\rho_{N}\left(n, q_{N}, q_{P}\right) x-D n \\
\dot{p}=D p_{i n}-\rho_{P}\left(p, q_{N}, q_{P}\right) x-D p \\
\dot{q_{N}}=\rho_{N}\left(n, q_{N}, q_{P}\right)-\mu\left(q_{N}, q_{P}\right) q_{N} \\
\dot{q_{P}}=\rho_{P}\left(p, q_{N}, q_{P}\right)-\mu\left(q_{N}, q_{P}\right) q_{P} \\
\dot{x}=\mu\left(q_{N}, q_{P}\right) x-D x
\end{array}\right.
$$

This general model structure accounts for various models described in the literature (Davidson and Gurney, 1999 , Legovic and Cruzado, 1997; Klausmeier et al. 2004b). In the model of Klausmeier et al. (2004b), the nutrient uptake rates $\rho_{P}\left(p, q_{N}, q_{P}\right)$ and $\rho_{N}\left(n, q_{N}, q_{P}\right)$ are represented by Michaelis-Menten kinetics:

$$
\rho_{P}\left(p, q_{P}\right)=\rho_{P \max }\left(q_{P}\right) \frac{p}{p+K_{S_{P}}} \text { and } \rho_{N}\left(n, q_{N}\right)=\rho_{N \max }\left(q_{N}\right) \frac{n}{n+K_{S_{N}}}
$$

where the maximum uptake rates $\rho_{P \max }$ and $\rho_{N \max }$ are down-regulated by 
the corresponding internal quota, using the original inhibition formulation of Gotham and Rhee (1981).

We will base our uptake model on hypotheses differing from the kinetics in equations 10. We will now introduce the chosen expressions for $\rho_{N}, \rho_{P}$ and $\mu$.

\subsection{Modeling of the growth rate}

We based our modeling approach on the assumption that $\mathrm{N}$ and $\mathrm{P}$ are both involved within a constant ratio in nucleic acids and particularly in RNA. Following the hypothesis that ribosome/RNA intra-cellular concentration is strongly correlated with growth rate (Klausmeier et al. 2004a), we assume that $\mathrm{N}$ or $\mathrm{P}$ can either limit growth depending on which of the two quotas is the most limiting. This hypothesis is supported by the results of Berdalet et al. (1994) on Heterocapsa sp. who found that both $\mathrm{N}$ and $\mathrm{P}$ starvation affected the RNA content.

We therefore assume, in line with Droop (1973, 1974) and Rhee (1978), that the most limiting nutrient will drive the growth rate, resulting in a minimum law:

$$
\mu=\min \left(\mu_{N}\left(q_{N}\right), \mu_{P}\left(q_{P}\right)\right)
$$

For sake of simplicity, we chose the following expression:

$$
\mu=\mu_{\max } \min \left(\frac{1-\frac{q_{N 0}}{q_{N}}}{1-\frac{q_{N 0}}{q_{N \exp }}}, \frac{1-\frac{q_{P 0}}{q_{P}}}{1-\frac{q_{P 0}}{q_{P \exp }}}\right)
$$

where parameters $q_{N \exp }$ and $q_{P \exp }$ represent the values of nitrogen and phosphorus quota for exponential growth when the growth rate has reached its maximum value $\mu_{\max }$.

As a consequence, we will assume in the steady-state analysis that the Nlimited growth rate is $\mu=\mu_{\max }\left(\frac{1-\frac{q_{N}}{q_{N}}}{1-\frac{q_{N 0}}{q_{N e x p}}}\right)$ while the P-limited growth rate is $\mu=\mu_{\max }\left(\frac{1-\frac{q_{P 0}}{q_{P}}}{1-\frac{q_{P 0}}{q_{P \exp }}}\right)$.

Hence, following Droop's theory (see equation 8), the limiting quota $q_{N}$ is an increasing function of the growth rate for $\mathrm{N}$-limited growth, while the limiting 
quota $q_{P}$ is an increasing function of the growth rate for P-limited growth. When $\mathrm{N}$ is in excess, the internal quota of $\mathrm{N}$ is called the saturated quota (the same term is used reciprocally for $\mathrm{P}$ when $\mathrm{P}$ is in excess).

\subsection{Modeling of the uptake rate}

The classical modeling for uptake of an external nutrient is the MichaelisMenten based modeling of Dugdale (1967).

$$
\rho\left(p, q_{P}\right)=\rho_{P \max }\left(q_{P}\right) \frac{p}{p+K_{p}}
$$

However, it was demonstrated that the combination of the Droop's equation for the growth rate and the Michaelis-Menten uptake kinetics greatly overestimates the experimental uptake rates for the non-limiting nutrient under extreme N:P ratios (Gotham and Rhee, 1981; Klausmeier et al., 2004b). Indeed, it is usual to consider that uptake of a nutrient can be down-regulated by its own internal quota (Morel, 1987). This reasoning leads to a slightly different uptake model, as developed by Lehman et al. (1975).

We therefore introduced a down-regulation term in the maximum P-uptake rate:

$$
\rho_{P \max }\left(q_{P}\right)=\bar{\rho}_{P \max } \frac{q_{P L}-q_{P}}{q_{P L}-q_{P 0}}
$$

where $q_{P L}$ is the hypothetical maximum value for the $\mathrm{P}$ quota and $\bar{\rho}_{P \max }$ is the maximum value of the uptake rate, when $q_{P}=q_{P 0}$. As Flynn (2008) pointed out, there is no particular reason for the critical level $q_{P L}$ to equal the Droopmaximum quota $q_{P \exp }$ (and this obviously holds for $q_{N L}$ also). Indeed, the data of Elrifi and Turpin (1985) showed that the maximum achievable quota of a non limiting nutrient could exceed the observed $q_{\exp }(6)$. For a given dilution rate, Elrifi and Turpin (1985) defined the luxury consumption capacity as the ratio of the saturated quota to the limiting quota. Luxury uptake was observed to be particularly high for $\mathrm{P}$ that could be stored in quantities up to 16 times the actual needs of Selenastrum minutum, while luxury consumption of N did not 
exceed 4 .

In conditions of nitrogen limitation and excess $\mathrm{P}$ supply $\left(P>>K_{S_{P}}\right)$, we obtain the following from equation $(9)$ :

$$
\dot{q}_{P}=\bar{\rho}_{P \max } \frac{q_{P L}-q_{P}}{q_{P L}-q_{P 0}}-D q_{P}
$$

and at steady-state, we can compute the saturated quota:

$$
q_{P}^{\star}=\frac{\bar{\rho}_{P \max } q_{P L}}{\bar{\rho}_{P \max }+D\left(q_{P L}-q_{P 0}\right)}
$$

It follows that the saturated $q_{P}^{\star}$ is a decreasing function of the dilution rate. From Droop's theory (see equation 8), the limiting $q_{N}^{\star}$ is an increasing function of the dilution rate, and consequently the saturated $q_{P}^{\star}$ is a decreasing function of the limiting $q_{N}^{\star}$. This has already been reported by Elrifi and Turpin (1985), who observed that the saturated phosphorus quota decreased for N-limited culture (see figure 1 ).

Remark 2: This conclusion is similar to what can be expected with the model of Klausmeier et al. (2004b), in the situation of excess P supply ( $P>>$ $K_{S_{P}}$ ). Indeed, the kinetics for phosphorus uptake are identical (see equation (10). Since, in both models, at steady state $\mu=D$, equation 16 also holds for the model of Klausmeier et al. (2004b), the predicted saturated phosphorus quota decreases with respect to $D$.

However the situation is different for nitrogen. Elrifi and Turpin (1985) showed that the saturated nitrogen quota of P-limited culture increases with the dilution rate (see figure 1). Our previous reasoning for P-limitation proves that the $\mathrm{N}$ uptake rate cannot be regulated solely by the internal nitrogen quota. Otherwise, it would lead to an equation similar to $(16)$, where the saturated $q_{N}^{\star}$ would decrease with $D$.

We will now explore another mechanism based on the idea that, as the transport of nitrate is active, it requires energy (i.e. ATP) and cofactors provided 
by the phosphorus pool (Crawford and Glass, 1998; Forde, 2000). Thus, the modeling of $\mathrm{N}$ uptake must reproduce the fact that the $\mathrm{P}$ quota of P-starved cells decreases and, as a consequence, the $\mathrm{N}$ uptake also decreases.

Therefore, we assume that the uptake of nitrogen is enhanced by the phosphorus quota:

$$
\rho_{N \max }\left(q_{N}, q_{P}\right)=\bar{\rho}_{N \max } \frac{q_{N L}-q_{N}}{q_{N L}-q_{N 0}} \frac{q_{P}-q_{P 0}}{q_{P L}-q_{P 0}}
$$

We can thus infer that, in transient situations where $\mathrm{P}$ becomes limiting, the P-status of the cells could induce a $\mathrm{N}$ uptake reduction leading to N-P colimitation. Conversely, when $q_{P}$ is high, the P-driven term allows a maximum potential for $\mathrm{N}$ uptake.

Let us compute the saturated quota $q_{N}^{\star}$ under P limitation. From equation 12 in P-limited conditions, the growth rate can be represented by the Droop model:

$$
\mu\left(q_{P}\right)=\bar{\mu}\left(1-\frac{q_{P 0}}{q_{P}}\right)
$$

At steady-state in the chemostat, when $\mathrm{N}$ is supplied in excess (i.e. $N>>$ $\left.K_{S_{N}}\right)$, we have $\rho_{N \max }\left(q_{N}^{\star}, q_{P}^{\star}\right)=\mu\left(q_{P}\right) q_{N}^{\star}$ :

$$
\bar{\rho}_{N \max } \frac{q_{N L}-q_{N}^{\star}}{q_{N L}-q_{N 0}} \frac{q_{P}^{\star}-q_{P 0}}{q_{P L}-q_{P 0}}=\bar{\mu}\left(1-\frac{q_{P 0}}{q_{P}^{\star}}\right) q_{N}^{\star}
$$

From this equation, the steady-state value of the saturated nitrogen quota can be computed as follows:

$$
q_{N}^{\star}=\frac{\bar{\rho}_{N \max } q_{P}^{\star}}{\bar{\mu}\left(q_{N L}-q_{N 0}\right)\left(q_{P L}-q_{P 0}\right)+\bar{\rho}_{N \max } q_{P}^{\star}} q_{N L}
$$

Thus, the saturated $q_{N}^{\star}$ is an increasing function of the limiting $q_{P}^{\star}$. Since, from equation (8), the limiting $q_{P}^{\star}$ is itself an increasing function of the dilution rate, it follows that the saturated $q_{N}^{\star}$ is increasing with the dilution rate. It is notable that this conclusion is the opposite to the decreasing behavior of the saturated $q_{P}^{\star}$ under $\mathrm{N}$ limitation. 
Remark 3: If we consider the model of (Klausmeier et al., 2004b) in the situation of excess $\mathrm{N}$ supply $\left(N>>K_{S_{N}}\right)$, we get from equation $(10)$ :

$$
0=\rho_{N \max } \frac{q_{N L}-q_{N}^{\star}}{q_{N L}-q_{N 0}}-D q_{N}^{\star}
$$

and therefore $q_{N}^{\star}=\frac{\bar{\rho}_{N \max } q_{N L}}{\bar{\rho}_{N \max }+D\left(q_{N L}-q_{N 0}\right)}$. As a consequence, the saturated $q_{N}^{\star}$ is a decreasing function of the dilution rate. This response is therefore opposite to our model prediction.

\section{Comparison of the model output with the experimental datasets}

\subsection{Qualitative comparison}

The chemostat experiments with Isochrysis affinis galbana under two extreme $\mathrm{N}: \mathrm{P}$ ratios gave contrasting patterns for the $\mathrm{N}$ and $\mathrm{P}$ quotas depending on the limiting nutrient. The steady-state carbon quota of cells was high at low growth rates and decreased to a minimum $\left(0.5\right.$ pmol.cell $\left.^{-1}\right)$ at $\mu=0.8 d^{-1}$. At low growth rates, the steady-state carbon quota appeared to be slightly larger under P limitation (0.9 pmol.cell $\left.^{-1}\right)$ than under $\mathrm{N}$ limitation $\left(0.8\right.$ pmol.cell $\left.^{-1}\right)$. The steady-state limiting quota for both $\mathrm{N}$ and $\mathrm{P}$ increased with growth rate, in agreement with the Droop theory. Steady-state non-limiting $\mathrm{P}$ quota was high at low growth rate under $\mathrm{N}$ limitation and declined with growth rate. The nonlimiting $\mathrm{P}$ quota was always higher than that required to support that growth rate. On the other hand, the steady-state non-limiting $\mathrm{N}$ quota increased with growth rate and reached a maximum value for the highest dilution rate tested. Our results emphasize that luxury consumption capacity was much higher for $\mathrm{P}$ than for $\mathrm{N}$. For all the dilution rates tested, the residual concentration of the non-limiting nutrient was high $(\mathrm{N}>160 \mu M$ and $\mathrm{P}>110 \mu M)$, while it was undetectable for the limiting nutrient.

Elrifi and Turpin (1985) observed the same behavior for limiting and nonlimiting quotas on Selenastrum minutum. They specified that ambient phosphorus was present $(40-60 \mu M)$ under nitrate limitation, and that nitrate was present (1.25-1.50 $\mathrm{mM}$ ) under phosphate limitation.

In both studies, the draw-down for the non-limiting nutrient was incomplete. 
The non-limiting quotas were always at their maxima and were assumed to be saturated. The maximum possible quota for $\mathrm{P}$ occurred at the lowest growth rate while the maximum $\mathrm{N}$ quota was achieved at $\mu_{\exp }$ and was equivalent to $q_{N \exp }$.

\subsection{Model calibration}

Model parameters were identified as follows. $\mu_{\max }$ for Selenastrum minutum was taken from Elrifi and Turpin (1985), and for Isochrysis affinis galbana it was determined from additional experiments. $q_{N 0}$ and $q_{P 0}$ and $\bar{\mu}_{N}$ and $\bar{\mu}_{P}$ were identified by fitting the experimental data to the standard Droop equation (7). $\bar{\rho}_{N \max }$ and $\bar{\rho}_{P \max }$ were computed from:

$$
\bar{\rho}_{\max }=\frac{\bar{\mu} \mu_{\max }}{\bar{\mu}-\mu_{\max }} q_{0}
$$

Finally, $q_{\text {Nexp }}$ and $q_{P e x p}$ where computed from equation (6).

The affinity constants $K_{S_{N}}$ and $K_{S_{P}}$ for Selenastrum minutum were taken from Nielsen (1978) and Ahlgren (1977) respectively. They were identified thanks to additional experiments for Isochrysis affinis galbana.

The values of $q_{P L}, q_{N L}, \bar{\rho}_{N \text { max }}$ and $\bar{\rho}_{P \max }$ have been adjusted in order to obtain the best fit between model predictions and steady-state measurements of $q_{P}$ and $q_{N}$.

\subsection{Quantitative comparison}

The model output was compared to the experimental datasets for saturated and limiting quotas at steady-state for both Isochrysis affinis galbana and Selenastrum minutum (Elrifi and Turpin, 1985). figure 1 and figure 2 demonstrate the ability of our model to correctly represent the experimental data of the two species both qualitatively and quantitatively (parameter values are given in table 21). The steady-state output of our model correctly reproduces the increasing trend of the limiting $q_{N}$ and $q_{P}$ and the strong asymmetry between the responses of the saturated quotas $q_{N}$ and $q_{P}$. 
Table 2: Parameter values used for model of N-P colimitation in Selenastrum minutum and Isochrysis affinis galbana.

\begin{tabular}{|c|c|c|c|}
\hline Parameter & \multicolumn{2}{|c|}{ Value } & Unit \\
\hline & S. minutum & I. aff. galbana & \\
\hline$\mu_{\max }$ & 1.68 & 1.5 & day $^{-1}$ \\
\hline$q_{n 0}$ & $610^{-2}$ & $6.510^{-2}$ & molN. molC -1 \\
\hline$q_{p 0}$ & $1.810^{-3}$ & $0.910^{-3}$ & molP. $\mathrm{molC}^{-1}$ \\
\hline$q_{N L}$ & 0.24 & 0.15 & molN. molC -1 \\
\hline$q_{P L}$ & 0.06 & 0.06 & molP. molC ${ }^{-1}$ \\
\hline$q_{N \exp }$ & 0.21 & 0.14 & molN. olC $^{-1}$ \\
\hline$q_{P \exp }$ & 0.015 & 0.006 & molP. $\mathrm{molC}^{-1}$ \\
\hline$\rho_{N \max }$ & 9.6 & 9.6 & molN.molC ${ }^{-1}$. day $^{-1}$ \\
\hline$\rho_{P \max }$ & $410^{-2}$ & $110^{-2}$ & molP.molC ${ }^{-1} \cdot$ day $^{-1}$ \\
\hline$K_{S_{N}}$ & $0.0510^{-6}$ & $0.110^{-6}$ & molN.L ${ }^{-1}$ \\
\hline$K_{S_{P}}$ & $0.025 \quad 10^{-6}$ & $0.05 \quad 10^{-6}$ & molP.L $\mathrm{L}^{-1}$ \\
\hline
\end{tabular}

We also fitted the experimental data for the two species with the model of Klausmeier et al. (2004b) extended with the uptake inhibition formulation of Gotham and Rhee (1981). figure 1 shows that, while this model succeeds in fitting the $\mathrm{N}$ and $\mathrm{P}$ limiting quotas and saturated $q_{P}$ correctly, it predicts a decline of the saturated $q_{N}$ with growth rate (as forecasted by our analytical computations and explained in Remark 3), which strongly contrasts with the increasing trend in the experimental data.

\section{Discussion}

\subsection{Asymmetry between $N$ and $P$ uptake}

Multi-nutrient limitation has recently become the focus of renewed attention. In the particular case of $\mathrm{N}$ and $\mathrm{P}$, there is experimental evidence for an asymmetric response between the $\mathrm{N}$ and $\mathrm{P}$ non-limiting quotas under $\mathrm{P}$ and $\mathrm{N}$ limitation respectively. An additional asymmetry is observed for the behavior of $q_{p}$ under $\mathrm{P}$ - and N-limited conditions, while the $q_{N}$ trend appears to be irrespective of what nutrient ( $\mathrm{N}$ or $\mathrm{P}$ ) is limiting growth. Most modeling approaches for phytoplankton growth have a symmetric formulation and therefore cannot describe the observed asymmetry (Droop, 1974 , Klausmeier et al. 2004b Smith 

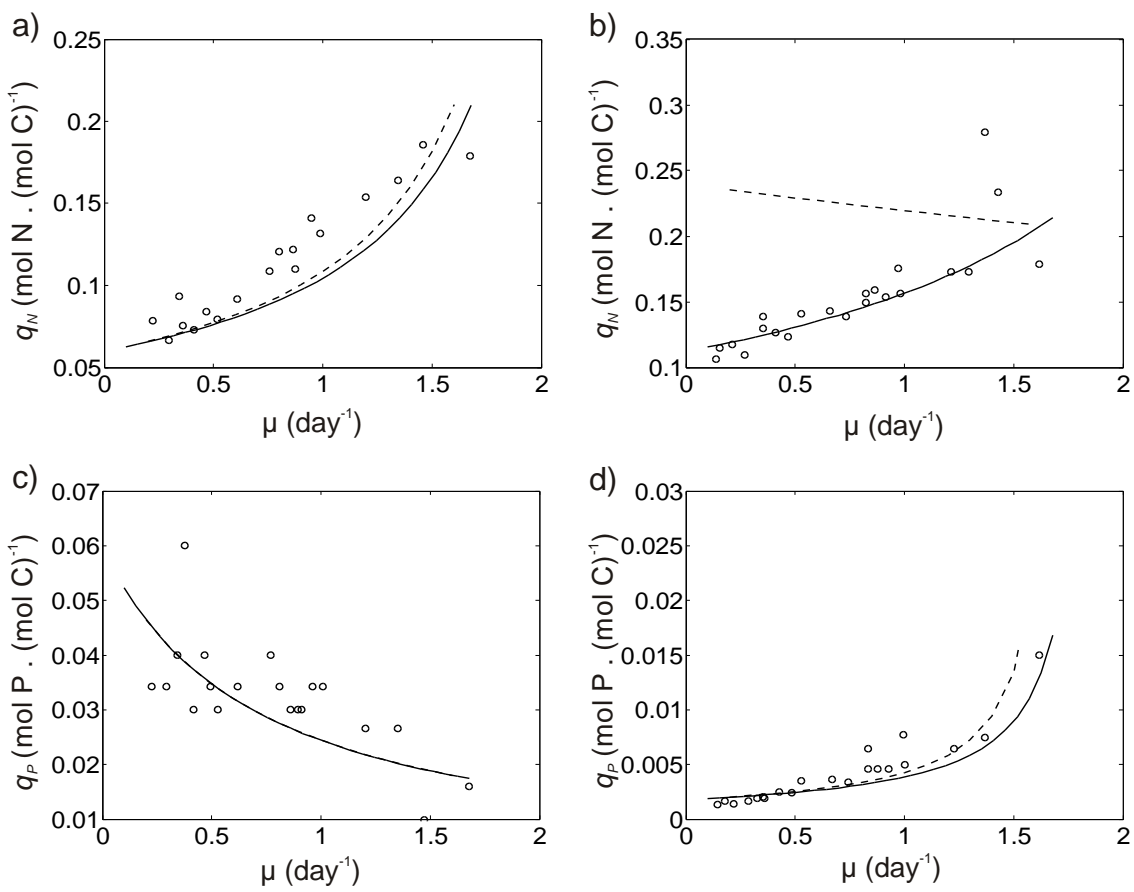

Figure 1: Comparison of the two models output with the experimental results for Selenastrum minutum at steady-state (Elrifi and Turpin 1985). The top figures show $q_{N}$ against $\mu$ under nitrogen limitation $(a)$ and phosphorus limitation $(b)$. The bottom figures show $q_{P}$ against $\mu$ under nitrogen limitation $(c)$ and phosphorus limitation $(d)$. Solid line : proposed colimitation model with parameter values as in table 2 Dashed line : model of Klausmeier et al. (2004b).

and Yamanaka, 2007). This was illustrated in the particular case of the model of Klausmeier et al. (2004b) with the experimental data of Elrifi and Turpin (1985).

The model proposed in the present paper is based on the idea, also developed by others (Agren, 2004, Davidson and Gurney, 1999; Pahlow and Oschlies, 2009), that a non-limiting nutrient can control the limitation exerted by another nutrient. Its asymmetric structure and simple formulation allow our model to successfully predict the qualitative and quantitative behavior of the limiting and non-limiting quotas observed for Selenastrum minutum and Isochrysis affnis galbana. It does so without discontinuity and without introducing a great number of supplementary parameters. Hence, in accordance with Pahlow and 

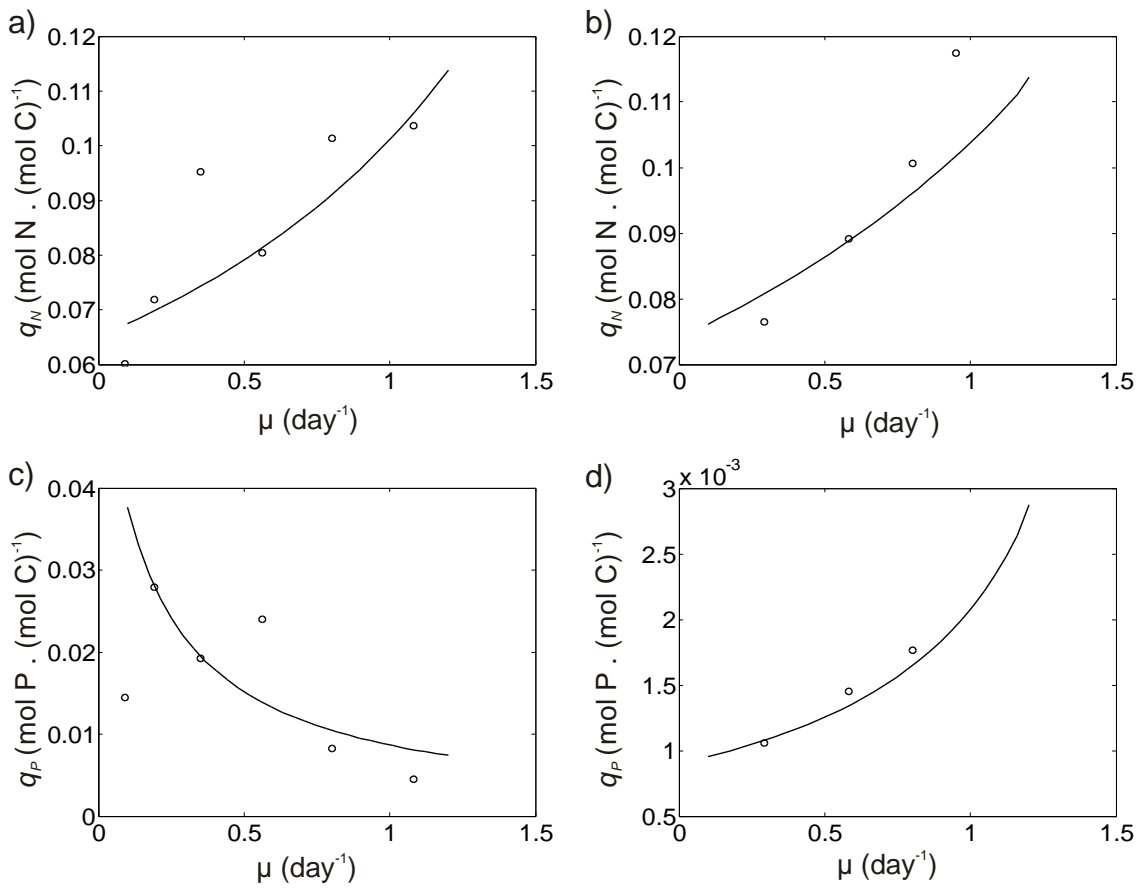

Figure 2: Comparison of the model output to the experimental results for Isochrysis affinis galbana at steady-state. The top two figures show $q_{N}$ against $\mu$ under nitrogen limitation $(a)$ and phosphorus limitation $(b)$. The bottom figures show $q_{P}$ against $\mu$ under nitrogen limitation $(c)$ and phosphorus limitation $(d)$. Parameter values used for the model are given in table 2

Oschlies (2009), but contrary to the classical assumption that N and P lead to independent limitation, we conclude that these two nutrients would be better considered as biochemically-dependent nutrients, as defined by Arrigo (2005) and Saito et al. (2008).

\subsection{Model prediction at physiological limit boundaries}

Phytoplankton cell nutrient quota at a given growth rate in the chemostat can vary between two boundaries. Indeed, if the growth is limited by the nutrient being considered, the internal quota is at its minimum level (Droop, 1968a). When this nutrient is in excess and growth is limited by another nutrient, cells accumulate the non-limiting nutrient up to a maximal quota. Hence, we can define the physiological limit boundaries (Elrifi and Turpin, 1985) as the maxi- 
mal and minimal attainable quota values for a given growth rate. Accordingly, the luxury consumption capacity, for a given growth rate can be defined from these physiological limit boundaries as the ratio of the maximum quota to the minimum quota.

Under the extreme N:P input-ratio tested experimentally with both Selenastrum minutum and Isochrysis affinis galbana, we assumed that the quota of the non-limiting nutrient was saturated, while the quota of the limiting nutrient was restricted to its minimum value for the given growth conditions. Therefore we can assume that the physiological limit boundaries were reached.

Under very low N:P input ratio, the model fits the data, with the saturated $q_{P}$ decreasing as the N-limited growth rate increases, according to equation (16). On the contrary, the experimental data of the saturated $q_{N}$ under P-limitation turned out to be an increasing function of the growth rate for both Selenastrum minutum and Isochrysis affinis galbana. The saturated- $q_{N}$ behavior matches the hypothesis of Droop (1983) that a non-limiting quota follows the Droop equation with a higher apparent $q_{N 0}$. As our analysis pointed out, the model of Klausmeier et al. (2004b), which only integrates the inhibiting effect of $q_{N}$ over $\mathrm{N}$ uptake, predicts a decreasing trend for the saturated- $q_{N}$ with the growth rate, as is observed for the saturated- $q_{P}$ under N-limiting conditions (see equation 16. Therefore, the limiting effect of $q_{P}$ on $\mathrm{N}$ uptake is necessary to fit the physiological boundaries correctly (equation 20). The asymmetric functions for $\mathrm{N}$ (structural) and $\mathrm{P}$ (functional) and particularly the energetic role of $\mathrm{P}$ at the acquisition level were therefore critical in our modeling approach. Thus, although the acquisition machinery is $\mathrm{P}$-poor, $\mathrm{P}$ appears to play a major role in the uptake of $\mathrm{NO}_{3}^{-}$.

The phenomenon of luxury consumption of inorganic nutrients by phytoplankton has been widely documented (Ketchum, 1939; Droop, 1974). figure 3a shows that the capacity of N-luxury consumption decreases with growth rate, as does $\mathrm{P}$ (figure $3 \mathrm{p}$ ). The capacity of N-luxury consumption has been reported 
a)

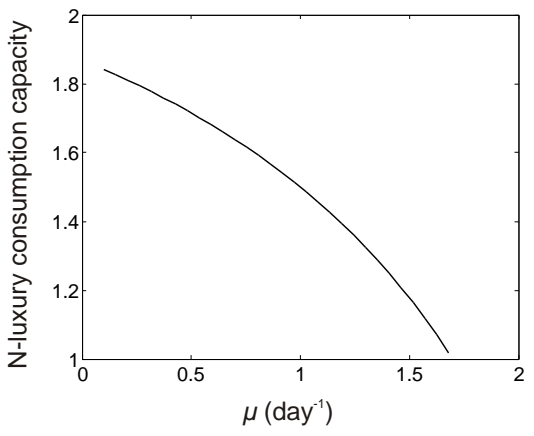

b)

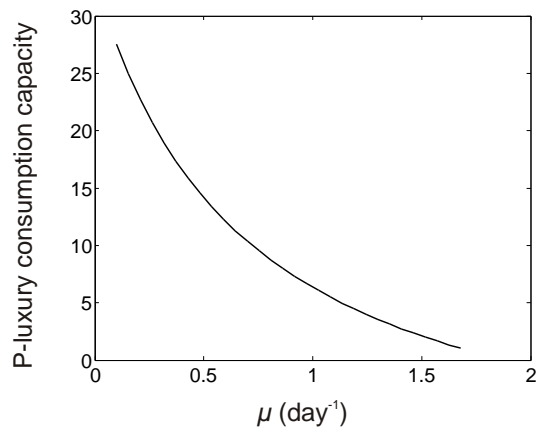

Figure 3: Model simulation of $\mathrm{N}(a)$ and $\mathrm{P}(b)$ luxury consumption capacities computed at steady-state against growth rate. The luxury consumption capacities were calculated for two extreme N:P input ratios (i.e. 1 and 100).

to be lower than that of $\mathrm{P}$ (Elrifi and Turpin, 1985; Terry, 1982) and our model succeeds in describing this difference.

\subsection{Model prediction inside the physiological limit boundaries}

In cases where $\mathrm{N}: \mathrm{P}$ input ratio is closer to the critical ratio for each species, one might suspect different behavior for the non-limiting quota, as it may not reach saturation. Indeed, the asymmetric structure of our model results in an asymmetric behavior for the non-limiting $q_{N}$ and $q_{P}$, as well as in uptake-control contrasts depending on (1) whether $\mathrm{N}$ or $\mathrm{P}$ is limiting and (2) the growth rate. $q_{P}$ varies according to the description of Klausmeier et al. (2004b): under Plimited growth rate or near the critical ratio, uptake-control is exerted solely by the low P-resource (i.e. $\left.P /\left(P+K_{p}\right)<1\right)$ and $q_{P}$ builds-up according to the Droop model (figure $4 \mathrm{p}$ for $\mathrm{N}: \mathrm{P}=10-100$ ).

Conversely, under $\mathrm{N}$-limited growth rate, the model predicts that $q_{P}$ may either increase or decrease, depending on the dilution rate and the N:P-input ratio in the chemostat. As long as $q_{P^{-}}$saturation is not achieved, uptake control 
is solely exerted by the low $\mathrm{P}$ resource. $q_{P}$ increases with growth rate because $\mathrm{P}$ resource increases (i.e.P $\left./\left(P+K_{p}\right)<1\right)$. Higher $\mathrm{N}$-limited growth rates can lead to situations where the P-uptake capacity then becomes limiting and $q_{P}$ decreases and converges towards $q_{P \exp }$ (see figure $4 \mathrm{p}$ for $\mathrm{N}: \mathrm{P}=2$ ).

Inside the physiological limit boundaries, N-uptake control under P-limited growth rate is even more complex because it is also governed by $q_{P}:$ at low $\mathrm{P}-$ limited growth rate, $\mathrm{N}$ uptake is strongly forced by both the limited N-resource (i.e. $\left.N /\left(N+K_{n}\right)<1\right)$ and the low ATP-pool that limits the activity of $\mathrm{N}$ porters (figure $4 \mathrm{a}$ ). Since both the available $\mathrm{N}$ and $\mathrm{P}$ resources increase with the P-limited growth rate, $q_{P}$ increases and favors uptake of the less limiting $\mathrm{N}$, which results in an increase of $q_{N}$ with growth rate. The mechanistic basis of our model therefore contrasts with the hypothesis of Klausmeier et al. (2004a) that P-limitation favors resource acquisition, at least for nitrate.

There are several other datasets in the literature that describe the response of $q_{P}$ and $q_{N}$ to growth rate under varying N:P ratio, but few are as comprehensive as the work of Elrifi and Turpin (1985), or investigated such low N:P ratios. Indeed, as far as we know, only the studies of Elrifi and Turpin (1985) and Rhee (1974) provided evidence that the physiological limit boundaries were reached.

Healey (1985) investigated a rather large range of N:P input ratio (2.5-100) in his study on the interacting effects of light and nutrient limitation on Synechococcus linearis. The data showed an increasing trend for both $\mathrm{N}-$ and $\mathrm{P}-$ limiting quotas with growth rate. The experimental non-limiting $q_{N}$ was confirmed to be an increasing function of the growth rate, with a rather higher apparent $q_{N 0}$, as predicted by our model and observed by Elrifi and Turpin (1985), but not by others (Laws and Bannister, 1980). Nevertheless, given the scatter in the data, the non-limiting $q_{P}$ of Synechococcus linearis exhibited no particular trend in the range of the growth rate tested. 
Goldman and Peavey (1979) demonstrated that N-limited continuous cultures of Dunaliella tertiolecta exhibit increasing (limiting) $q_{N}$ and (non-limiting) $q_{P}$ with growth rate under $\mathrm{N}: \mathrm{P}$ ratios ranging from 5 to 15 . However, the authors clearly specified that "virtually all the influent $\mathrm{PO}_{4}^{3-}$ was stripped from the medium at all the values of $\mu$ up to $1.1 d^{-1}$ \%. This makes it possible to infer that the physiological limit boundary was not attained and that $q_{p}$ was not saturated, even under the lowest N:P ratio tested. Calculations based on the dataset of Healey (1985) seem to indicate that ambient $\mathrm{PO}_{4}^{3-}$ was remaining under $\mathrm{N}$ limitation. Nevertheless, since Healey (1985) did not give any direct indications for ambient $\mathrm{PO}_{4}^{3-}$ it can hardly be ascertained whether $q_{p}$ was saturated or not.

Interestingly, the model predicts striking modifications for $q_{p}$ behavior near the limit physiological boundary even for a small increase of the N:P-input ratio in the range 1 to 10 . The relatively high values for the minimal N:P-input ratio tested by Goldman and Peavey (1979) $(\mathrm{N}: \mathrm{P}=5)$ and Healey (1985) (N:P = $2.5)$ could explain why none of the authors observed the typical decrease in the saturated $q_{P}$ at the physiological boundary, as predicted by the model. Indeed, it is clear from figure $4 \mathrm{~b}$ that under input ratio values of 2 and $5, q_{p}$ increases for low growth rates and decreases for higher growth rates. In his experiment on $\mathrm{P}$ uptake under nitrate limitation by Scenedesmus.sp in a chemostat, Rhee (1974) investigated N:P ratios as low as 1:1. Unfortunately, due to the scatter in the data for $q_{P}$ and because the quota is given as cell quota rather than carbon-based quota, it is difficult to ascertain whether these data support the model's decreasing trend for saturated $q_{P}$ or not.

Our model highlights an important feature for $q_{P}$ : conversely to $q_{N}$, the $q_{P}$ behavior is very sensitive to the $\mathrm{N}: \mathrm{P}$ input ratio. On one hand, a slight increase of extremely low $\mathrm{N}: \mathrm{P}$ input ratio can result in striking modifications in the $q_{P}$ behavior. On the other hand, under N-limited growth but close to the critical ratio, $q_{P}$ remains rather constant with growth rate (see figure 4 for $\mathrm{N}: \mathrm{P}=5$ ). 
a)

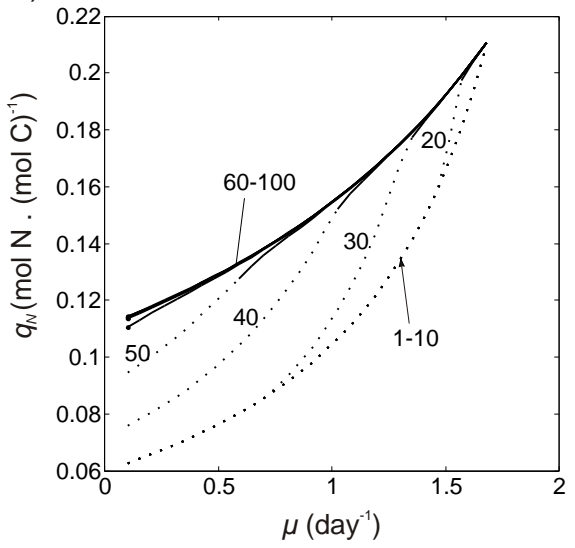

b)

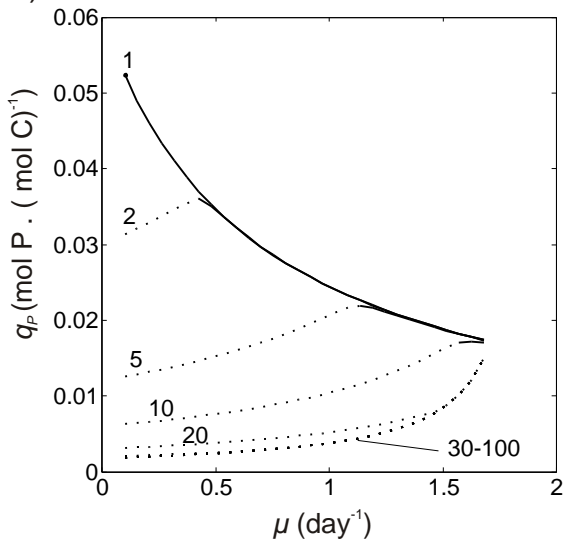

Figure 4: Model predictions for the steady-state $\mathrm{N}$ quota $(a)$ and $\mathrm{P}$ quota $(b)$ against growth rate under different $\mathrm{N}: \mathrm{P}$ input ratio ranging from 1 to 100 . Numbers represent the values of the N:P input ratio. Dotted-lines represent situations where uptake is substratelimited $\left(S /\left(S+K_{S}\right)<0.9\right)$. The solid lines represent situations where the uptake-capacity is limiting.

This result has significant implications for experiments aiming to examine N-P colimitation, which should be designed so as to guarantee that the physiological limit boundaries are actually attained.

Figure 5 shows simulation results for the variations of $q_{N}: q_{P}$ against growth rate under different input N:P ratios ranging from 1 to 100 . At low growth rates $q_{N}: q_{P}$ remains equivalent to the input ratio as long as the input ratio falls within the physiological limit boundaries and neither of the two nutrients is limiting. Increase in growth rate results in alteration of the $q_{N}: q_{P}$ ratio driven by the physiological limit boundaries to the quota, as we described above for extreme N:P input ratios.

\subsection{Comparison with other $N-P$ colimitation models}

The mechanisms of N-P colimitation remain ambiguous, because $\mathrm{N}$ and $\mathrm{P}$ are involved together in many biochemical processes. Different modeling approaches were thus proposed for N-P colimitation over the last decade. Some 


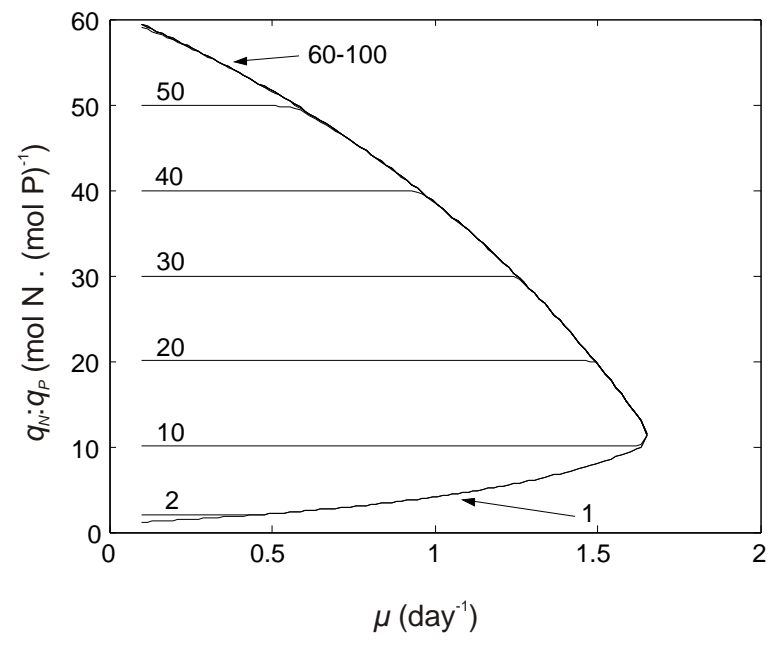

Figure 5: Steady-state predictions for the $q_{N}: q_{P}$ ratio against growth rate under different $\mathrm{N}: \mathrm{P}$ input ratio ranging from 1 to 100 . Numbers represent the values of the $\mathrm{N}: \mathrm{P}$ input ratio.

of these converged towards the hypothesis that interaction between nutrients takes place at the acquisition level, which characterizes the interface between the environment and the intracellular compartment (Flynn, 2008; Klausmeier et al. 2004b, 2007, Smith and Yamanaka, 2007). On the other hand, both Agren (2004) and Pahlow and Oschlies (2009) developed models based on the idea that colimitation occurs in the assembly machinery.

Several models of colimitation have been based on the Droop theory and since Droop (1973, 1974) and Rhee (1978) demonstrated that the multiplicative law generally underestimates growth rate, the growth function was often represented as a minimum law rather than the multiplicative one (Davidson and Gurney, 1999; Klausmeier et al., 2004b, Smith and Yamanaka, 2007). In addition, an internal quota down-regulation of the uptake system was sometimes incorporated into the model to prevent overestimation of the quota for the non-limiting nutrient (Davidson and Gurney, 1999: Gotham and Rhee, 1981 . Klausmeier et al., 2004b). Smith and Yamanaka (2007) used an alternate nutrient uptake model, built on the affinity-based uptake model Aksnes and Egge, 
1991 Pahlow, 2005 where phytoplankton allocate internal $\mathrm{N}$ between surface uptake sites and internal enzymes in the same proportion for all nutrients. This model was in good agreement with the fitted data of Droop (1974) and Rhee (1974), except at the extreme N:P ratios where it did not perfectly agree with the data of Rhee.

Interestingly, the model of Klausmeier et al. (2004b) reproduced the behavior of $q_{P}$ under $\mathrm{N}$ and $\mathrm{P}$ limiting conditions, with general trends resembling those of our model. Nevertheless, as our analysis pointed out, the same behavior was assumed for $q_{N}$, although non limiting $q_{N}$ was experimentally demonstrated to be an increasing function of the growth rate, even under very high N:P ratio (Elrifi and Turpin, 1985, Healey and Hendzel, 1975, Terry, 1982).

Another important feature for models of N-P colimitation is their ability to describe the asymmetry between non-limiting $\mathrm{N}$ and $\mathrm{P}$ quotas. Hence, the modeling approaches can be categorized into two broad types depending on whether they include a symmetric or an asymmetric formulation for the different nutrients. The classical multiplicative formulation of multi-nutrients models induces a symmetric behavior for the different nutrients and is, therefore, inappropriate for describing N-P colimitation. Conversely, as discussed by Pahlow and Oschlies (2009), the threshold model, which links growth rate to the quota of a suboptimal resource, could principally achieve asymmetry but this is not mechanistically based and would restrict the range of $q_{N}: q_{P}$ ratios observed experimentally. Flynn (2008) approached the asymmetry of the non limiting $q_{P}$ and $q_{N}$ observed by Elrifi and Turpin (1985) for Selenastrum minutum with a twostate model, where the uptake functions were of the classical Michaelis-Menten type for the limiting nutrients, and were multiplied by a function depending on $q_{N}$ and $q_{P}$ in order to reproduce the kinetic of the non limiting quota.

Very recently, Pahlow and Oschlies (2009) developed a chain model that includes $\mathrm{P}$-control of N-assimilation in terms of the affinity-based uptake function, and where $q_{N}$ ultimately determines growth rate. These authors based their mod- 
eling approach on the idea that the $\mathrm{P}$ content of ribosomes could act as the mechanistic link between $q_{P}$ and $\mathrm{N}$ assimilation, as proposed by Agren (2004). This model succeeds in describing the asymmetric behavior of $q_{P}$ and $q_{N}$ for a range of experimental datasets for different phytoplankton species.

Here we propose another mechanism: that active $\mathrm{N}$ uptake can be regulated by the cellular P tied to the ATP-pool. Although the P fraction is low in the acquisition machinery, there are strong indications in the literature that nutrient uptake can compete with C-fixation for ATP. Falkowski and Stone 1975) showed that a pulse of either $\mathrm{NO}_{3}^{-}$or $\mathrm{NH}_{4}^{+}$resulted in a transitory decrease in carbon fixation per unit chlorophyll $a$ for natural phytoplankton. Additional experiments with an uncoupler of the two light reactions led him to infer that cyclic photophosphorylation is a primary energy source for $\mathrm{NO}_{3}^{-}$uptake. Davies and Sleep (1989) also performed pulse-experiments on simultaneously N- and P-starved Skeletonema costatum. The authors reached the same conclusion as Falkowski and Stone (1975) that a pulse of either $\mathrm{NH}_{4}^{+}$or $\mathrm{NO}_{3}^{-}$resulted in a decrease in the steady-state rate of carbon fixation. On the other hand, the joint addition of $\mathrm{N}$ and $\mathrm{P}$ resulted in a large stimulation of carbon fixation. Davies and Sleep (1989) assumed that the uptake of nitrogen was itself phosphate limited and that, under conditions of extreme and continuing phosphorus limitation, the repression of carbon fixation would be expected to be long-lasting. A similar decrease of carbon fixation rates for different inorganic nutrients has also been reported by several other investigators (Glover et al. 2007, Smalley et al. 2003. Beardall et al. 2001). Thus, pulse-experiments and particularly that of Davies and Sleep (1989) support our hypothesis that, under P limitation, competition for ATP occurs between $\mathrm{N}$ uptake and dark reactions.

One may suspect a more direct relationship between $\mathrm{N}$ and $\mathrm{P}$ uptake. Indeed, Terry (1982) demonstrated an asymmetric interaction between $\mathrm{N}$ and $\mathrm{P}$ uptake on Pavlova lutheri, where $\mathrm{P}$ uptake could inhibit $\mathrm{N}$ uptake, whereas $\mathrm{N}$ uptake had no effect on $\mathrm{P}$ uptake. The severity of $\mathrm{PO}_{4}^{3-}$-uptake inhibition of 
$\mathrm{NO}_{3}^{-}$-uptake increased with the preconditioning $\mathrm{N}: \mathrm{P}$ ratio (i.e. the lower the $q_{P}$, the higher the N-uptake inhibition). Terry (1982) postulated that the inhibition of $\mathrm{NO}_{3}^{-}$-uptake by $\mathrm{PO}_{4}^{3-}$-uptake may result from the allocation of a limited energy resource rather than from a direct action of $\mathrm{PO}_{4}^{3-}$ on the $\mathrm{NO}_{3}^{-}$ uptake system. As reflected by our uptake modeling, under P-limited steadystate where $q_{P}$ is low, $\mathrm{P}$ uptake could directly compete with $\mathrm{N}$ uptake for the limited available energy.

Additionally, Perry (1976) showed that the ATP:C ratio in Thalassiosira pseudonana was consistently lower in P-limited than in N-limited chemostat cultures, while the ATP:P ratio remained unaffected. Hunter and Laws (1981) and Laws et al. (1983) also recorded with Thalassiosira weissflogii that, under $\mathrm{P}$ limitation, the ATP: $\mathrm{C}$ ratio was about 30 to over 50 percent lower than under $\mathrm{N}$ limitation, especially for low growth rate. It is worth noting that, in the two latter studies, ATP analyses were corrected for alkaline phosphatase activity (Karl and Craven 1980) which may induce a drop in ATP:C ratio under P limitation. Hunter and Laws (1981) concluded that "the relationship between ATP:C ratios and growth rate is highly dependent on the factor limiting growth, at least at moderate or low growth rates". These results confirm $q_{P}$ as an indicator of the ATP pool level in the cell.

Our model specifies that under $\mathrm{N}$ limitation, the high $\mathrm{P}$ quota enhances $\mathrm{N}$ uptake, which we interpret as a high availability of ATP for cellular functions. However, investigation of the ATP pool by itself is not sufficient to reflect the metabolic rate within the cell : competition for ATP allocation between the different cell functions depends on the balance between (1) the level of metabolic and overall energy demand and (2) the level of available ATP pool. We define an indicator $A_{A T P}$ of ATP availability relative to the rate of carbon fixation, computed as the ratio of $A T P$ : $C$ to growth rate. Calculations of $A_{A T P}$ (Figure 6) on the basis of the results of Perry (1976), Hunter and Laws (1981) and Laws et al. (1983), show that (1) $A_{A T P}$ is a decreasing function of growth rate 
a)

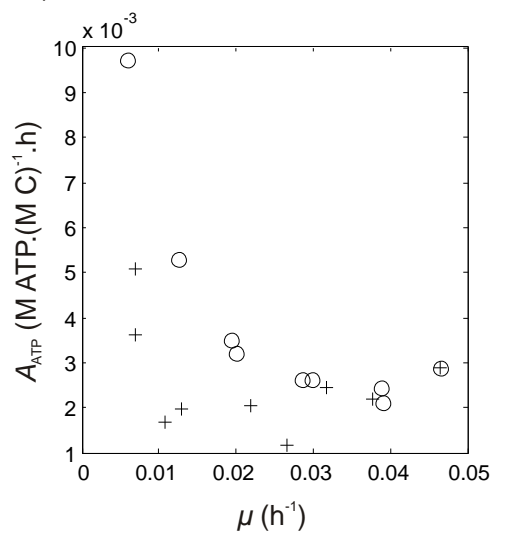

b)

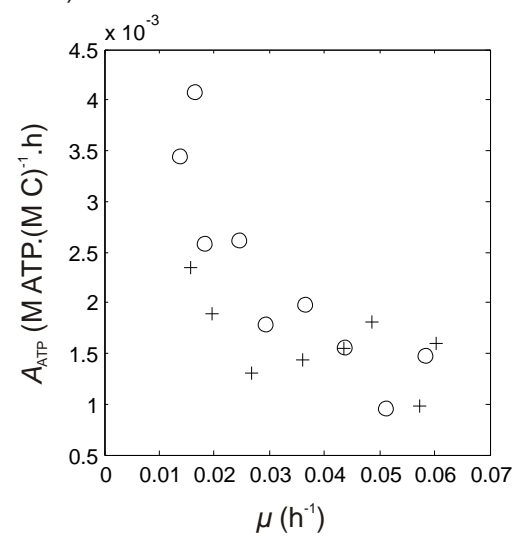

Figure 6: Computed steady-state $A_{A T P}$ for Thalassiosira weissflogii under $\mathrm{P}$ limiting $(+)$ and N limiting conditions (o). Data from Hunter and Laws (1981) (a) and from Laws et al. (1983) (b).

under N-limiting conditions and that (2) it is rather stable with growth rate under P limiting conditions (except perhaps for very low growth rates), (3) being generally lower under $\mathrm{P}$ limitation than under $\mathrm{N}$ limitation, especially at low growth rates. In the study of Hunter and Laws (1981) with Thalassiosira weissflogii, $A_{A T P}$ under $\mathrm{P}$ limitation is only half that under $\mathrm{N}$ limitation for the lowest growth rates tested. The same trends are observed in Laws et al. (1983), although the scatter in the data makes the conclusions more delicate. Hence, one can infer that under $\mathrm{N}$ limitation, (1) competition for energy between the cellular functions is lower than under $\mathrm{P}$ limitation and that (2) competition is an increasing function of growth rate, as ATP availability is reduced due to the energy demand growing faster than the ATP pool. Moreover, Dai et al. (2008) recently demonstrated that the adenylate energy charge (the metabolic energy stocked in the adenine nucleotide pool) of Microcystis aeruginosa is an increasing function of the P-limited growth rate. From these various biological observations, one can expect that the restricted ATP-pool under P-limited growth should enhance the competition for ATP of (1) N uptake with carbon fixation and (2) between $\mathrm{N}$ and P-uptake systems. We therefore conclude that 
the behavior of $q_{P}$ with growth rate qualitatively reflects the competition for energy between the cellular functions and these findings justify the $q_{P}$ regulation in our $\mathrm{N}$ uptake modeling approach (17).

The biological results presented above motivated the asymmetric formulation for the two uptake functions. Our model assumes that no interactions occur between $\mathrm{N}$ status and $\mathrm{P}$ uptake and that, therefore, $\mathrm{P}$ uptake is solely governed by the internal P quota, as observed by Terry (1982). Indeed, the model fitted sufficiently well with the experimental data that it was concluded that such an additional interaction was not necessary to the model. Additionally, under phosphorus limitation, it was suggested that the constrained energy pool was preferentially allocated to $\mathrm{P}$ uptake rather than $\mathrm{N}$ uptake or carbon fixation.

There are various indications of competition for energy between the two functional machineries and between the active $\mathrm{N}$ - and P-uptake systems. These observations, together with the demonstration of Rhee $(1978)$ that the minimum law correctly predict growth rate under different N:P ratios, led us to (1) consider the N-P interaction at the acquisition level rather than at the assembly level and (2) choose the minimum law for growth rate in our modeling of N-P colimitation.

Our analysis suggests that important traits of phytoplankton N-P colimitation can be captured under the assumption that competition for energy is the main link between $\mathrm{N}$ and P. Nevertheless, the complexity and the diversity of N-P interactions raise the question of multi-level interactions and of the pre-eminent process for N-P colimitation. Further investigations are needed to elucidate these particular points. Experiments investigating energy charge, RNA content and short-term uptake measurements on chemostat cultures under varying and extreme N:P ratios should offer new insights. As our analysis pointed out, in agreement with Elrifi and Turpin (1985), the achievement of quota saturation (related to the range of N:P ratio explored) is a crucial condi- 
tion for a better understanding of phytoplankton N-P colimitation. Under these extreme conditions, it would be interesting to confirm the model prediction that phytoplankton stoichiometry deviates from the input N:P ratio, particularly at very low dilution rates.

\section{Conclusion}

We proposed a new model of N-P colimitation. This Droop-based model hypothesizes that the interaction between $\mathrm{N}$ and $\mathrm{P}$ should be considered at the acquisition level rather than the assembly level. Indeed, we conclude that the Droop function between growth rate and quota remains unaffected by the N-P interaction, although $\mathrm{N}$ quota is largely determined by the cellular $\mathrm{P}$ status. The $\mathrm{P}$ control on $\mathrm{N}$ uptake through energy availability needed for $\mathrm{NO}_{3}^{-}$porters combined with a negative retroaction of quota level on nutrient uptake allowed the model to reproduce the experimental data of Elrifi and Turpin (1985) and of experimental trials in the present study, made under extreme N:P input ratios. Furthermore, our uptake-based approach emphasizes that assimilation did not have to be modeled separately from uptake to reproduce the asymmetry between $\mathrm{N}$ and $\mathrm{P}$. We therefore suggest that, regarding the colimitation concept, $\mathrm{N}$ and $\mathrm{P}$ would better be considered as dependent nutrients rather than biochemically independent ones.

As several authors already pointed out (Flynn, 2008, Klausmeier et al. 2007 , Leonardos and Geider, 2005) there is a critical need for new experimental data considering $\mathrm{N}$ and $\mathrm{P}$ under different and extreme input ratios and growth rates.

Acknowledgments: This paper presents research results supported by the ANR-06-BIOE-014 Shamash project. The authors are grateful to Julie Marchetti for the experimental dataset with Isochrysis affinis galbana. 


\section{References}

Afghan, B. K., 1982. Nutrients. In: Van Loon, J. C. (Ed.), Chemical Analysis of Inorganic Constituents of Water. CRC press, West Palm Beach, Fla, pp. $170-178$.

Agren, G. I., 2004. The c:n:p stoichiometry of autotrophs - theory and observations. Ecology Letters 7, 185-191.

Ahlgren, G., 1977. Growth of oscillatoria agardhii in chemostat culture: 1. nitrogen and phosphorus requirements. Oikos 29 (2), 209-224.

Aksnes, D., Egge, J., 1991. A theoretical model for nutrient uptake in phytoplankton. Mar. Ecol. Prog. Ser. 70, 65-72.

Arrigo, K. R., 2005. Marine microorganisms and global nutrient cycles. Nature $437,349-355$.

Beardall, J., Berman, T., Heraud, P., Kadiri, M. O., Light, B. R., Patterson, G. W., Roberts, S., Sulzberger, B., Sahan, E., Uehlinger, U., Wood, B., 2001. A comparison of methods for detection of phosphate limitation in microalgae. Aquatic Sciences 63, 107-121.

Berdalet, E., Latasa, M., Estrada, M., 1994. Effects of nitrogen and phosphorus starvation on nucleic acid and protein content of Heterocapsa sp. J. Plankton Res. 16, 303-316.

Bergstrom, A. K., Jonsson, A., Jansson, M., 2008. Phytoplankton responses to nitrogen and phosphorus enrichment in unproductive swedish lakes along a gradient of atmospheric nitrogen deposition. Aquatic Biology 4 (1), 55-64.

Bernard, O., A.Sciandra, Madani, S., 2008. Multimodel analysis of the response of the coccolithophore Emiliania huxleyi to an elevation of $\mathrm{pCO}_{2}$ under nitrate limitation. Ecol. Model. 211, 324-338. 
Bernard, O., Gouzé, J. L., 1995. Transient Behavior of Biological Loop Models, with Application to the Droop Model. Mathematical Biosciences 127 (1), 1943.

Bernard, O., Gouzé, J.-L., 1999. Nonlinear qualitative signal processing for biological systems: application to the algal growth in bioreactors. Math. Biosciences $157,357-372$.

Bernard, O., Sallet, G., Sciandra, A., 1998. Nonlinear observers for a class of biological systems. application to validation of a phytoplanktonic growth model. IEEE Trans. Aut. Cont. 43, 1056-1065.

Bougaran, G., Bernard, O., Sciandra, A., 2009. Modelling continuous cultures of microalgae colimited with nitrogen and phosphorus. In: Proceedings of the Mathmod 09 conference. Vienna, Austria.

Bougaran, G. L., Le Dean, L., Lukomska, E., Kaas, R., Baron, R., 2003. Transient initial phase in continuous culture of Isochrysis galbana affinis Tahiti. Aquatic Living Resources 16 (4), 389-394.

Burmaster, D., 1979. The unsteady continuous culture of phosphate-limited Monochrisis lutheri droop : Experimental and theoretical analysis. Journal of Experimental Marine Biology and Ecology 39 (2), 167-186.

Crawford, N. M., Glass, A. D. M., 1998. Molecular and physiological aspects of nitrate uptake in plants. trends in plant science 3, 389-395.

Dai, R., Liu, H., Qu, J., Zhao, X., Ru, J., Hou, Y., 2008. Relationship of energy charge and toxin content of Microcystis aeruginosa in nitrogen-limited or phosphorous-limited cultures. Toxicon 51 (4), 649-658.

Davey, M., Tarran, G. A., Mills, M. M., Ridame, C., Geider, R. J., LaRoche, J., 2008. Nutrient limitation of picophytoplankton photosynthesis and growth in the tropical north atlantic. Limnology and Oceanography 53 (5), 1722-1733. 
Davidson, K., Gurney, W. S. C., 1999. An investigation of non-steady-state algal growth. ii. mathematical modelling of co-nutrient-limited algal growth. Journal of Plankton Research 21 (5), 839-858.

Davies, A. G., Sleep, J. A., 1989. The photosynthetic response of nutrientdepleted dilute cultures of Skeletonema costatum to pulses of ammonium and nitrate; the importance of phosphate. J. Plankton Res. 11, 141-164.

Droop, M., 1968a. Vitamin b12 and marine ecology. iv. the kinetics of uptake, growth and inhibition in monochrysis lutheri. J. Mar. Biol. 48, 689-733.

Droop, M. R., 1968b. Vitamin B12 and marine ecology. IV. the kinetics of uptake growth and inhibition in Monochrysis lutheri. J. Mar. Biol. Assoc. 48 (3), 689-733.

Droop, M. R., 1973. Some thoughts on nutrient limitation in algae. Journal of Phycology 9, 264-272.

Droop, M. R., 1974. The nutrient status of algal cells in continuous culture. Mar. Biol. Asooc. U.K. 54, 825-855.

Droop, M. R., 1983. 25 years of algal growth kinetics. a personnal view. Botanica Marina 26, 99-112.

Dugdale, R. C., 1967. Nutrient limitation in the sea: dynamics, identification and significance. Limnol. Oceanogr. 12, 685-695.

Elrifi, I. R., Turpin, D. H., 1985. Steady-state luxury consumption and the concept of optimum nutrient ratios : a study with phosphate and nitrate limited Selenastrum minutum (chlorophyta). J. Phycol. 21, 592-602.

Elser, J., Marzolf, E., Goldman, C., 1990. Phosphorus and nitrogen limitation of phytoplankton growth in the freshwaters of north america: A review and critique of experimental enrichments. Can. J. Fish. Aquat. Sci. 47 (7), 14681477. 
Falkowski, P. G., Stone, D. P., 1975. Nitrate uptake in marine phytoplankton: Energy sources and the interaction with carbon fixation. Marine Biology $32(1), 77-84$.

Flynn, J. K., 2008. The importance of the form of the quota curve and control of non-limiting nutrient transport in phytoplankton models. J. Plankton Res. $30,423-438$.

Forde, B. G., 2000. Nitrate transporters in plants : structure, function and regulation. Biochimica et Biophysica Acta 1465, 219-235.

Geider, R. J., LaRoche, J., 2002. Redfield revisited : variability of c:n:p in marine microalgae and its biochemical basis. European Joural of Phycology $37,1-17$.

Glover, H. E., Garside, C., Trees, C. C., 2007. Physiological responses of sargasso sea picoplankton to nanomolar nitrate perturbations. J. Plankton Res. 29 (3), 263-274.

Goldman, J. C., Peavey, D. G., 1979. Steady-state growth and chemical composition of the marine chlorophyte Dunaliella tertiolecta in nitrogen-limited continuous cultures. Applied and Environmental Microbiology 38, 894-901.

Gotham, I. J., Rhee, G.-Y., 1981. Comparative kinetic studies of phosphatelimited growth and phosphate uptake in phytoplankton in continuous culture. Journal of Phycology 17, 257-265.

Healey, F. P., 1985. Interacting effects of light and nutrient limitation on the growth rate of synechococcus linearis (cyanophyceae). Journal of Phycology $21(1), 134-146$.

Healey, F. P., Hendzel, L. L., 1975. Effect of phosphorus deficiency on 2 algae growing in chemostats. Journal of Phycology 11, 303-309.

Hunter, B. L., Laws, E. A., 1981. Atp and chlorophyll a as estimators of phytoplankton carbon biomass. Limnology and Oceanography 26 (5), 944-956. 
Karl, D. M., Craven, D. B., 1980. Effects of alkaline phosphatase activity on nucleotide measurements in aquatic microbial communities. Appl. Environ. Microbiol. 40 (3), 549-561.

Ketchum, B. H., 1939. The absorption of phosphate and nitrate by illuminated cultures of Nitzschia closterium. American Journal of Botany 26 (6), 399-407.

Klausmeier, C. A., Litchman, E., Daufresne, T., Levin, S. A., 2004a. Optimal nitrogen-to-phosphorus stoichiometry of phytoplankton. Nature 429, 171-174.

Klausmeier, C. A., Litchman, E., Levin, S. A., 2004b. Phytoplankton growth and stoichiometry under multiple nutrient limitation. Limnology and Oceanography 49, 1463-1470.

Klausmeier, C. A., Litchman, E., Levin, S. A., 2007. A model of flexible uptake of two essential resources. Journal of Theoretical Biology 246, 278-289.

Lange, K., Oyarzun, F. J., 1992. The attractiveness of the Droop equations. Mathematical Biosciences 111, 261-278.

Laws, E. A., Bannister, T. T., 1980. Nutrient- and light-limited growth of thalassiosira fluviatilis in continuous culture, with implications for phytoplankton growth in the ocean. Limnology and Oceanography 25 (3), 457-473.

Laws, E. A., Karl, D. M., Redalje, D. G., Jurick, R. S., Winn, C. D., 1983. Variability in ratios of phytoplankton carbon and rna to atp and chlorophyll a in batch and continuous cultures. Journal of Phycology 19 (4), 439-445.

Legovic, T., Cruzado, A., 1997. A model of phytoplankton growth on multiple nutrients based on the michaelis-menten-monod uptake, droop's growth and liebig's law. Ecological Modelling 99 (1), 19-31.

Lehman, J., Botkin, D., Likens, G., 1975. The assumptions and rationales of a computer model of phytoplankton population dynamics. Limnology and Oceanography 20 (3), 343-364. 
Leonardos, N., Geider, R. J., 2005. Elemental and biochemical composition of Rhodomonas reticulata (cryptophyta) in relation to light and nitrate-tophosphate supply ratios. J. Phycol. 41, 567-576.

Maberly, S. C., King, L., Dent, M. M., Jones, R. I., Gibson, C. E., 2002. Nutrient limitation of phytoplankton and periphyton growth in upland lakes. Freshwater Biology 47, 2136-2152.

Morel, F. M. M., 1987. Kinetics of nutrient uptake and growth in phytoplankton. Journal of Phycology 23, 137-150.

Nielsen, E. S., 1978. Growth of plankton algae as a function of n-concentration, measured by means of batch technique. Marine Biology 46 (3), 185-189.

Pahlow, M., 2005. Linking chlorophyll-nutrient dynamics to the redfield n:c ratio with a model of optimal phytoplankton growth. MEPS 287, 33-43.

Pahlow, M., Oschlies, A., 2009. Chain model of phytoplankton p, $\mathrm{n}$ and light colimitation. Mar. Ecol. Prog. Ser. 376, 69-83.

Perry, M. J., 1976. Phosphate utilization by an oceanic diatom in phosphoruslimited chemostat culture and in oligotrophic waters of central north-pacific. Limnology and Oceanography 21 (1), 88-107.

Persic, V., Horvatic, J., Has-Schon, E., Bogut, I., 2009. Changes in n and p limitation induced by water level fluctuations in nature park kopacki rit (croatia): nutrient enrichment bioassay. Aquatic Ecology 43 (1), 27-36.

Ren, L., Rabalais, N. N., Turner, R. E., Morrison, W., Mendenhall, W., 2009. Nutrient limitation on phytoplankton growth in the upper barataria basin, louisiana: Microcosm bioassays. Estuaries and Coasts 32 (5), 958-974.

Rhee, G. Y., 1974. Phosphate uptake under nitrate limitation by Scenedesmus sp. and its elcolgical implications. J. Phycol 10, 470-475. 
Rhee, G. Y., 1978. Effects of n:p atomic ratios and nitrate limitation on algal growth, cell composition, and nitrate uptake. Limnology and Oceanography $23,10-24$.

Saito, M. A., Goepfert, T. J., Ritt, J. T., 2008. Some thoughts on the concept of colimitation: Three definitions and the importance of bioavailability. Limnol. Oceanogr. 53, 276-290.

Sciandra, A., Ramani, P., 1994. The limitations of continuous cultures with low rates of medium renewal per cell. J. Exp. Mar. Biol. Ecol. 178, 1-15.

Seppala, J., Tamminen, T., Kaitala, S., 1999. Experimental evaluation of nutrient limitation of phytoplankton communities in the gulf of riga. Journal of Marine Systems 23, 107-126.

Smalley, G. W., Coats, D. W., Stoecker, D. K., 2003. Feeding in the mixotrophic dinoflagellate ceratium furca is influenced by intracellular nutrient concentrations. Marine Ecology-Progress Series 262, 137-151.

Smith, S. L., Yamanaka, Y., 2007. Optimization-based model of multinutrient uptake kinetics. Limnol. Oceanogr. 54 (4), 1545-1558.

Suttle, C., Harrison, P., 1988. Ammonium and phosphate uptake rates, n:p supply ratios, and evidence for $\mathrm{n}$ and $\mathrm{p}$ limitation in some oligotrophic lakes. Limnology and Oceanography 33 (2), 186-202.

Terry, K. L., 1980. Nitrogen and phosphorus requirements of Pavlova lutheri in continuous culture. Botanica Marina 23, 757-764.

Terry, K. L., 1982. Nitrate and phosphate uptake interactions in a marine prymnesiophyte. J. Phycol. 18, 79-86.

Vatcheva, I., deJong, H., Bernard, O., Mars, N., 2006. Experiment selection for the discrimination of semi-quantitative models of dynamical systems. Artif. Intel. 170, 472-506. 
Zohary, T., Herut, B., Krom, M. D., Mantoura, R. F. C., Pitta, P., S. Psarra, F. R., Stambler, N., Tanaka, T., Thingstad, T. F., Woodward, E. M. S., 2005. P-limited bacteria but $\mathrm{n}$ and $\mathrm{p}$ co-limited phytoplankton in the eastern mediterranean-a microcosm experiment. Deep Sea Research Part II: Topical Studies in Oceanography On the Nature of Phosphorus Cycling and Limitation in the Eastern Mediterranean 52, 3011-3023. 